\title{
Using privacy calculus theory to explore entrepreneurial directions in mobile location-based advertising: Identifying intrusiveness as the critical risk factor
}

Anabel Gutierrez ${ }^{a^{*}}$, Simon O'Leary ${ }^{b}$, Nripendra P. Rana ${ }^{c}$, Yogesh K.

Dwivedi ${ }^{\mathrm{c}}$, Tatiana Calle ${ }^{\mathrm{b}}$

${ }^{a}$ Kent Business School, University of Kent, ME4 4TE, United Kingdom

${ }^{\mathrm{b}}$ Entrepreneurship \& Family Business Research Centre, Regent's University

London, NW1 4NS, United Kingdom

${ }^{\mathrm{C}}$ Emerging Markets Research Centre (EMaRC), School of Management, Swansea University Bay Campus, SA1 8EN, United Kingdom

\begin{abstract}
Location-based advertising is an entrepreneurial and innovative means for advertisers to reach out through personalised messages sent directly to mobile phones using their geographic location. The mobile phone users' willingness to disclose their location and other personal information is essential for the successful implementation of mobile location-based advertising (MLBA). Despite the potential enhancement of the user experience through such personalisation and the improved interaction with the marketer, there is an increasing tension between that personalisation and mobile users' concerns about privacy. While the privacy calculus theory (PCT) suggests that consumers make privacy-based decisions by evaluating the benefits any information may bring against the risk of its disclosure, this study examines the specific risks and benefits that influence consumers' acceptance of MLBA. A conceptual model is proposed based on the existing literature and a standardised survey was developed and targeted at individuals with known interests in the subject matter. From these requests, 252 valid responses were received and used to evaluate the key benefits and risks of MLBA from the users' perspectives. While the results confirmed the importance of internet privacy concerns (IPC) as an important determinant, they also indicate that monetary rewards and intrusiveness have a notably stronger impact on acceptance intentions towards MLBA. Intrusiveness is the most important risk factor in determining mobile users' intentions to
\end{abstract}


accept MLBA and therefore establishing effective means of minimising the perceived intrusiveness of MLBA can be expected to have the greatest impact on achieving effective communications with mobile phone users.

Keywords: Mobile location-based advertising (MLBA); privacy calculus theory (PCT); internet privacy concerns (IPC); intrusiveness; personalisation; monetary rewards; General Data Protection Regulation (GDPR).

\section{Introduction}

At over $17 \%$, digital advertising was the fastest growing advertising segment in 2016 (IABUK, 2017), with mobile advertising increasing from under \$29 billion in 2015 to over $\$ 40$ billion in 2016 (eMarketer, 2016). This provided a significant incentive for marketers to migrate towards mobile communication platforms that allow for more personal, interactive and virtually instant communications compared to traditional marketing communications (Chaffey \& Chadwick, 2012). One of the most recent advances in this channel is mobile location-based advertising (MLBA), which offers consumers benefits such as personalised communications that are tailored to the mobile user's real-time geographic location (Krishen et al., 2017; Lee \& Rha, 2016; Unni \& Harmon, 2007). Additionally, mobile-influenced sales and actual sales figures through mobile commerce (m-commerce) have shown a sustained growth (IABUK, 2017) and this

further supports the transition of advertising revenues to mobile platforms. However, by accepting permission at the download stage, users share personal information such as device ID, call log information, address book contacts and location, possibly even granting some control requests such as the ability to vibrate the device (Gu et al., 2017; Woottrich et al., 2018). Mobile devices facilitate data collection that can be shared with other entities such as application developers, analytics companies and advertisers (Woottrich et al., 2018). This can trigger privacy concerns for the user, particularly when businesses or official public bodies hold such personal information (Krishen et al., 2017; Limpf \& Voorveld, 2015; Zhao, Lu, \& Gupta, 2012). Moreover, the General Data Protection Regulation (GDPR) approved in 2016 with enforcement date on May 2018 (EU-DPR, 2016) has enhanced the relevance of this issue and all organisations now need to develop better understandings of mobile users' perceptions, behaviours and rights. 
The tension between the personalisation of advertising and mobile users' privacy/security represents the personalisation-privacy paradox (PPP), with users having the opportunity to share personal information in exchange for retail value and personalised services (Barth \& Jong, 2017; Sutanto et al., 2013). Prior research on PPP has focused on it through the lens of the privacy calculus theory (PCT) (Keith et al., 2010; Xu et al., 2011) on the basis that consumers make privacy-based decisions by evaluating the benefits any information may bring against the risk of its disclosure (Pentina et al., 2016; Zhu et al., 2017). This theory assumes that privacy-related decision-making is a rational process. However, prior research shows that privacy practices are not fully integrated, leading to irrational approaches with little or no risk assessment (Barth \& Jong, 2017). Although research has found that the privacy decision is influenced by contextual factors and user personality (Lee \& Rha, 2016; Wang et al., 2016), it is also shown that perceived benefits have more significant influence than the perceived risks/costs (Wang et al., 2016). In MLBA, the focus of this research, concerns pivots around the potential risk that mobile users experience concerning potential breaches of confidentiality regarding their personal data, including their location. When downloading an app, users may be unaware of the risks that privacy-invasive apps deliver. However, when they receive personalised ads that acknowledge their location, this becomes apparent and implies that consumers are able to evaluate the risks/benefits.

While some studies indicate that privacy is the primary concern for MLBA, negatively influencing an individual's stated intention to disclose personal information and therefore stalling the potential consumption of personalised applications (Keith et al., 2013; Sheng, Nah, \& Siau, 2008; Sun et al., 2015), other studies indicate that the potential benefits gained through such personalisation could outweigh privacy concerns (Baek \& Morimoto, 2012; Wang et al., 2016; Xu et al., 2011). Nevertheless, contradictory results indicate that this is not the case for personalised advertising (Lee \& Rha, 2016) and the specific factors affecting the acceptance of MLBA have not been fully investigated. The intention to not disclose information tends to be often overridden in practice to obtain immediate benefits (Keith el at., 2013; Wottrich et al., 2018) as most mobile users are 
willing to disclose information to be able to use the app or receive a promotion or discount (Premazzi et al., 2010; Ward, Bridges \& Chitty, 2005; Zhu et al., 2017).

To better understand consumers' acceptance of MLBA and the perceived privacy concerns regarding personal information disclosure, a fundamental requirement for the application of MLBA, this study empirically explores the drivers that influence MLBA acceptance intentions. By applying the PCT and using a targeted survey methodology, this research focuses on privacy risk, in the form of IPC and intrusiveness, and exchange benefits, as represented by personalisation and monetary rewards. The following section reviews the extant literature on the PPP and proposes a conceptual model of MLBA acceptance, together with corresponding hypotheses. This is followed by the research methodology. The results section details the hypothesis testing conducted. Further discussion and implications are presented to support the conclusions, limitations and suggestions for further research.

\section{Literature review and hypotheses}

The PCT has been widely used to provide a better understanding of how consumers evaluate the fairness of disclosing personal information to marketers (Keith et al., 2010; Sun et al., 2015; Xu et al., 2011), claiming that consumers arrive at their privacy decisions by weighing up the potential benefits against the potential risks that may be generated by the disclosure of their personal information (Pentina et al., 2016). This is a variant of the equity or justice theory which claims that the justice perceptions of an individual are derived from the ratio between benefits and cost (Adams, 1963; in Sun et al., 2015). Low privacy risks result in a perception of a higher benefit and therefore justice. Conversely, consumers are more likely to perceive information disclosure as being unjust when privacy risks are relatively high, despite recognising the benefits of disclosing the said information (Sun et al., 2015).

The notion of privacy is a key influence on information disclosure (Lowry et al., 2012; Shah, Peikari, \& Yasin, 2014) and, in the online environment, privacy refers to individuals' awareness and control of the collection and usage of personal data (Hann et 
al., 2007). More specifically, Hong and Thong (2013) identified six IPC factors (data collection, secondary usage, error, improper access, control and awareness), emphasising control and awareness as the principal dimensions of concern. Additionally, Smith, Dinev, \& Xu (2011) saw privacy of information as a binary choice between those who wished to remain anonymous by keeping their personal information private and those who viewed information privacy as a form of control. The view that privacy can be conceptualised as a commodity (Davies, 1997; Zhu et al., 2017) that can be traded has gained popularity (Jentzsch, Preibusch, \& Harasser, 2012; Smith, Dinev, \& Xu, 2011). This latter view is implying that an individual's decision to willingly disclose private information is made by balancing the risk of disclosing information against the benefits that sharing of this information could bring them (Keith et al., 2013). Furthermore, sharing personal data is considered an increasing part of contemporary life (EU-DPR, 2016) and consumer behaviour is evolving in the face of such entrepreneurial innovations.

Prior studies demonstrated that a user's decision to download a new app is not always a rational process where careful analysis of the risks and benefits associated with information trade are considered. Instead, the decision is influenced by external forces such as time constraints, immediate gratification or optimistic bias leading to the acceptance of benefits while ignoring the risks (Barth \& Jong, 2017; Wottrich et al., 2018). As users become experienced with mobile apps, some focus on the benefits and tend to negate the downside of the perceived risks. With MLBA, users may not have been aware of the trade-off of personal data when downloading an app. However, receiving a tailored message when passing a specific location raises awareness of how their personal data is used (Barth \& Jong, 2017). This research focuses on the rational assessment of riskbenefit calculations (Privacy Calculus Theory) that consumers may conduct to decide upon the acceptance or non-acceptance of this type of contact.

Behavioural intent has been defined as "the strength of one's intention to perform a specified behaviour" (Fishbein \& Ajzen, 1975 in Sultan, Rohm, \& Gao, 2009, p.288). In relation to this paper, behavioural intent is concerned with how willing a consumer is to disclose personal information that is both dynamic (current location data) and static (such 
as name, shopping history, address book contents and other information), to generate the receipt of promotional offers or product/information-related marketing communications via mobile devices. Therefore, the key outcome variable in this study is MLBA acceptance, as measured by the behavioural intent towards MLBA.

Building upon previous studies' findings that applied the PCT in the electronic commerce and mobile context (Dinev et al., 2013; Kim, 2008; Li, Sarathy, \& Xu, 2011; Petina et al., 2016), this research evaluates the key risk and benefit components for MLBA, a specific context not previously researched. The premise is that both perceived risks and benefits influence users' acceptance of MLBA.

\subsection{Risks and benefits}

In the e-commerce context, perceived risk has been defined as the uncertainty, discomfort and/or anxiety discerned by users when they cannot anticipate the consequences of disclosing personal information online (Geetha \& Rangarajan, 2015). Such disclosure is even greater in the mobile context because it can allow the detection of location, time of day and the presence of other connected individuals in the vicinity (Pentina et al., 2016). Although perceived risk has been conceptualised as a multidimensional concept involving financial, performance, physical, physiological and social risk (Jacobby \& Kaplan, 1972; in Sun et al., 2015), this research focuses on the privacy concerns as a particularly salient facet in the MLBA context.

In the PCT, willingness to disclose information is negatively associated with perceived risk and positively associated with perceived benefit. By disclosing locationbased information with marketers, consumers may benefit from receiving personalised advertisements (Zhao et al., 2012) tailored to the mobile users' interests, activities, locations and time of day, as well as communications about monetary rewards (Premazzi et al., 2010; Ward, Zhu et al., 2017), each of these driving up the number of users open to MLBA. On the other hand, because location-related information is highly sensitive (Zhao et al., 2012), users may be worried about their personal information being misused 
or may perceive location-based advertising as intrusive, a potential consequence of which being a refusal to disclose information and therefore not be open to MLBA.

\subsection{IPC risks}

IPC refer to the degree to which internet users are concerned about how, and to what extent, their personal information is collected and used by an online entity (Malhotra, Sung, \& Agarwal, 2004). This implies that there is a perceived difference between users' expectations of how their personal information is being handled and the reality of its handling.

There are several concerns that come into play in the context of online marketing which may hinder mobile users' acceptance of MLBA. Previous research has identified six main dimensions that shape IPC (Hong \& Thong, 2013), namely data collection, secondary usage, improper access, error, control and awareness. Data collection is defined as the degree to which a person is concerned about the amount of individualspecific data possessed by an online entity; Secondary usage of data as the extent to which an individual is concerned that personal information is collected for one purpose, but used for another purpose or shared with third parties without authorisation; Improper access of data as the degree to which a person is concerned about their personal data being stolen or available to people not authorised; Error, as the degree to which a person is concerned about the accuracy of the personal information and methods to correct and keep personal data without errors; Control refers to the degree to which a person is concerned that he or she does not have adequate control over his or her personal information and how it is collected and used by others; Awareness of data usage represents an individual's understanding of privacy terms and conditions, lack of informed consent and non-transparency on data processing practices.

IPC are of importance in the context of MLBA, given that MLBA involves, not only the collection of personal information, but also location information, which is considered highly sensitive by many individuals as it could increase the risk of information misuse (Fodor \& Brem, 2015; Junglas, Johnson, \& Spitzmuller, 2008; Zhu et al., 2017). Of 
particular concern for users of some mobile apps is the sharing of personal information such as postings, photos, location and payment details (Wang et al., 2016). It has also been reported that some location-based promotion service providers, such as Groupon.com, are losing some customers who are not comfortable with their online footprint being tracked (Zhu et al., 2017). Therefore, it can be expected that MLBA will be perceived negatively by people with high IPC who are likely to view the tracking and storage of location information as a threat to their freedom and privacy.

H1: IPC has a negative and significant impact on mobile phone users' acceptance intentions towards MLBA.

\subsection{The intrusiveness risk}

The perceived intrusiveness of a mobile message is critical, as intrusiveness is negatively related to advertisement value (Okazaki, Li, \& Hirose, 2009). Intrusiveness is a psychological construct that embraces the notion of creating an imbalance between the independence of the two parties and the autonomy to safeguard personal identity (Woottrich et al., 2018). This is different from the concept of privacy, as users may react negatively due to experienced loss of freedom or because the app restricts autonomous decision about the type of information they share. Intrusiveness, in the context of MLBA, can be defined as a psychological reaction to unsolicited location-based advertisements and communications sent to users' mobile phones that interfere with users' ongoing cognitive processing (Truong \& Simmons, 2010). Some mobile apps force acceptance permission before usage is enabled and do not allow the user to control how much personal data the app is collecting. This represents an intrusion in the sense that the user has no autonomous decision to share information (Woottrich et al., 2018). Such intrusiveness leads to negative emotions, such as disturbance and irritation, and behavioural effects such as advertisement avoidance or refusal of permission request (Edwards, Li, \& Lee, 2002; Wehmeyer, 2007), even if they have agreed to receive them, as the user experiences a loss of freedom (Rau et al., 2011; Varnali, 2012; Woottrich et al., 2018). More specifically, perceived intrusiveness can be seen as: distracting; disturbing; forced; interfering; intrusive; and obtrusive (Truong \& Simmons, 2010). 
H2: Intrusiveness of mobile advertising has a negative and significant impact on mobile phone users' acceptance intentions towards MLBA.

\subsection{The personalisation benefits}

The adoption of a technology is highly dependent upon the benefits that the technology offers (Rogers, 1995 in Beldad \& Kusumadewi, 2015). In this study, perceived benefit refers to the perception of positive outcomes arising from disclosing location and personal information online. Perceived benefit relates to motivational factors, which can be utilitarian or hedonic, that induce positive satisfaction (Lee, Park, \& Kim, 2013). Zhao, Lu \& Gupta (2012) argue that the perceived benefit can outweigh the perceived risk of using location-based services. Previous research (Barth \& Jong, 2017) found that personalisation, convenience, economic benefits and social advantages suppress perceptions of risk and enhance feelings of benefit.

Personalisation is identified as a utilitarian benefit, brought about by the disclosure of personal information (Sun et al., 2015). According to Junglas \& Watson (2006), personalisation enhances user experience and makes interacting with the marketer far more efficient. In this way personalisation provides "more precise alternatives for them to compare the price, quality, relevance, and other characteristics before a purchase decision, thus also reducing their searching costs" (Zhu et al., 2017). In the context of personalised advertisements, systems automatically track, gather and explicitly use everyone's personal information to deliver tailored advertising messages based on the user profile (Sundar \& Marathe, 2010; Xu, Liao, \& Li, 2008). By sending the consumer messages that are tailored to their interests, identity, location and time, MLBA offers the benefits of contextualisation, enabling greater communication between the marketer and consumer, leading to greater business opportunities. In the context of this research, two components of anticipated benefits will be used; locatability, which covers aspects such as location and time, and content relevance, which stems from users' profiles.

Locatability means the ability to correlate users' online activity by date and time 
with their geographic locations. A reflection of this is when the check-in function of Facebook allows marketers to undertake location-based marketing (Wang et al., 2016). Such advertising is perceived by consumers both positively and negatively ( $\mathrm{Xu}$ et al., 2009). Time, a temporal dimension, and location, a spatial dimension, have been identified as critically important factors in successful MLBA campaigns (Wang et al., 2016) and messages with an appropriate context have a greater positive impact upon the consumer (Hühn et al., 2017; Lee, Kim, \& Sundar, 2015). In addition, this temporal dimension helps to stimulate unplanned purchases since consumers are more likely to consider a mobile promotion that matches their situational context, such as for example connecting through the store logo to receive a discount (Andrews et al., 2016; Wang et al., 2016).

The other key anticipated benefit is content relevance, which refers to the degree to which MLBA is uniquely tailored to the target consumers' preferences and needs (Xu et al., 2009). Banerjee \& Dholakia (2008), suggest that the more relevant a message is perceived by the consumer, the easier it is to process due to the activation of familiar knowledge, thus enhancing its appeal. Moreover, it has been found that the more involved the consumer is regarding the subject of the communication, the more likely they are to attend to it (Park \& Goering, 2016). For example, tourist recommendations systems that are effectively using customer profiles can recommend relevant points of interest to improve trip experiences (Wang et al., 2016). In this way, involvement largely determines the relevance and usefulness of an advertisement (Lee, Kim, \& Sundar, 2015). Involvement includes product involvement and personal relevance (Atkinson, 2013). Past research suggests that if a consumer is involved with the subject of the communication, this generates a more positive attitude towards it, leading to greater cognitive processing and an increased willingness to process the message (Albert, Goes, \& Gupta, 2004; Lee, Kim \& Sundar, 2015).

Regarding personal relevance, messages that reflect customers' own needs are perceived as pleasant and likeable (Kim \& Han, 2014). Additionally, customers prefer personalised messages that are relevant to their lifestyle and based on their interests as 
that eases the decision-making process, especially when customers are able to choose what information they receive (Gazley, Hunt, \& McLaren, 2015; Robins, 2003). Xu, Oh and Teo (2009) suggest that advertising that targets customers according to their consumption pattern can result in a higher response rate. Therefore, it is vital that marketing techniques keep up-to-date consumer-profiles and remain aware of their shopping habits and needs.

Based on these arguments, it is therefore proposed that personalised advertising, which provides relevant content at the right place and time, should be more effective in producing a positive response from the target consumer.

H3: Personalisation has a positive and significant impact on mobile phone users' acceptance intentions towards MLBA.

\subsection{The monetary reward benefits}

Empirical evidence from research into the privacy concerns of consumers shows that such concerns can be reduced by compensating the consumer for disclosing private information, thus enhancing their benefit perception (Hann et al., 2007; Hui, Teo, \& Lee, 2007). Premazzi et al. (2010) signal that consumers are more likely to relinquish some privacy in exchange for monetary rewards. Monetary rewards refer to currency or currency-equivalent rewards such as coupons, discounts, vouchers and gift certificates (Lee et al., 2013). Indeed, Xie et al. (2006) posit that the most influential factor in the disclosure of information is monetary reward. This is important because it suggests that, through the application of incentives, a consumer may be influenced to disclose information that they had previously wanted to keep private, thereby reducing or eliminating the issue of privacy concerns (Koohikamali, Gerhart, \& Mousavizadeh, 2015; Zhu et al., 2017).

It has been found that consumers will exchange one interpersonal resource (love; status; information; money; goods; services) for another if such an exchange maximizes their wins (Donnenwerth \& Uriel, 1974 in Xu et al., 2011; Wang et al., 2016). Furthermore, 
financial compensations may represent additional benefits for consumers, on top of contextualized messages, in exchange for personal information (Wang et al., 2016). Hence, although monetary rewards may alert consumers to the fact that their personal and location data is being collected, this may also compensate for any perceived privacy concerns due to the existence of a mutually beneficial exchange (Barth \& Jong, 2017; Hung \& Wong, 2009). Therefore, it is argued that, by providing monetary rewards, it is possible to increase consumers' willingness to disclose information and accept MLBA.

H4: Monetary reward has a positive and significant impact on mobile phone users' acceptance intentions towards MLBA.

The conceptual model and the preceding hypothesis are summarized in Fig. 1 below.

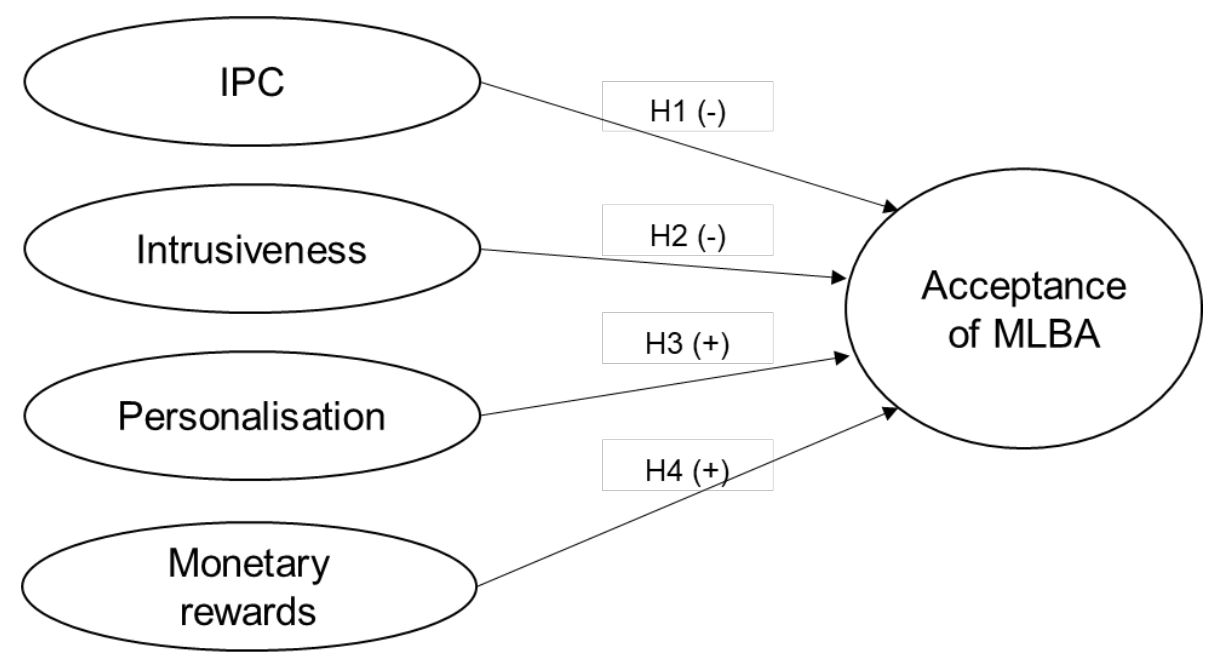

Fig. 1. MLBA acceptance conceptual model.

\section{Research Method}

A series of related questions were developed from previous research and progressively tested in pilot evaluations with colleagues. These questions evolved into a survey that covered each of the key constructs. In addition, careful considerations were given to identifying suitable target groups for the completed survey and suitable data processing techniques were identified and prepared. Once the survey, targets and processing means were identified, the data collection began. 


\subsection{Data collection and sample characteristics}

Data collection was conducted using a standardised survey over a two-week period. The survey was distributed electronically via email and social networking sites, including Facebook, Twitter and Instagram, to 823 potential participants. Additionally, digital marketing groups on Linkedln were targeted: The Location-Based Services (LBS) Zone of 858 members; and the Location-Based Advertising (LBA) discussion group of 789 members. These groups, together with selected members of the authors' networks, provided a potential knowledgeable target population of 2,470 members who were considered highly likely to be aware of the relevant issues. Gazley, Hunt \& McLaren (2015) indicate that the use of social networking as a survey distribution channel is suitable, as it uses social ties to facilitate reflective sampling.

The survey recorded 252 responses, all of which were usable for this investigation as they provided fully completed questionnaires. This indicates an overall response rate of $10.2 \%$, representative of similar online surveys (Kaplowitz et al., 2004). Table 1 provides an overview of the demographic distribution of the sample and shows that $82 \%$ of respondents were aware of MLBA, with $62 \%$ having already received this type of communication.

\section{Table 1}

Sample characteristics. 


\begin{tabular}{|c|c|c|c|}
\hline Characteristic & & Frequency & Percentage (\%) \\
\hline Nationality group by areas: & & & \\
\hline $\begin{array}{l}\text { Europe (UK, Norway, Italy } \\
\text { Switzerland, others) }\end{array}$ & rance, & 184 & 73.0 \\
\hline $\begin{array}{l}\text { The Americas (USA, Colo } \\
\text { Canada. Venezuela. Brazil) }\end{array}$ & ia, Mexico, & 45 & 17.8 \\
\hline Others & & 23 & 9.1 \\
\hline Gender & Female & 151 & 59.9 \\
\hline & Male & 101 & 40.1 \\
\hline Age group & Under 25 & 70 & 27.8 \\
\hline & $25-34$ & 95 & 37.7 \\
\hline & $35-44$ & 38 & 15.1 \\
\hline & 45 plus & 49 & 19.4 \\
\hline Prior awareness of MLBA & No & 44 & 17.5 \\
\hline & Yes & 208 & 82.5 \\
\hline Already received a MLBA & No & 95 & 37.7 \\
\hline & Yes & 157 & 62.3 \\
\hline Allow mobile location & Always & 33 & 13.1 \\
\hline tracking & Never & 21 & 8.3 \\
\hline & Sometimes & 198 & 78.6 \\
\hline
\end{tabular}

\subsection{Survey development and measurements}

The survey introduced examples of MLBA to ensure participants understand how personal data, including location, is used to personalise ads. Of the total 39 questions, six were related to the demographics of the respondent (nationality, gender and age group), their knowledge of MLBA (awareness and experience) and their preference for allowing mobile tracking. The remaining 33 questions were designed to measure their acceptance of the MLBA model, using a 5-point Likert scale, ranging from 1 'strongly disagree' to 5 'strongly agree'. Each construct was represented by multiple scale items based on existing measures validated in prior mobile advertising studies (Appendix A).

Privacy concern items were derived from Hong \& Thong (2013), consisting of collection of data (three-items), errors in personal data (three-items) and control (threeitems), in the context of various personalisation services online. Three mobile advertising items were based on Kim \& Han's (2014) work on the intrusiveness of a mobile 
advertisement message. Content relevance was assessed using items from $\mathrm{Xu}$ et al. (2009) and Lee \& Rha's (2016) research on location-based advertising effectiveness. The locatability construct was based on previous studies that had focused on attitudes towards location-based services (Kim \& Han, 2014; Xu et al., 2009; Xu et al., 2011). The monetary rewards value was measured using Ünal, Ercis, \& Keser's (2011) three-items scale for mobile advertising attitudes, and the scale used to measure acceptance intentions towards MLBA was based on Xu, Liao \& Li's (2008) measured acceptance of personalised mobile advertising.

\section{Results}

\subsection{Confirmatory factor analysis (CFA)}

A CFA was conducted to test the proposed model in Fig. 1 using AMOS 22.0. The CFA exhibited that all the selected items loaded favourably on their corresponding constructs and provided convincing empirical evidence of their validity. The high factor loading (i.e. $>0.5$ ) confirmed the conditions for convergent validity (Kline, 2011). Further assessment of average variance extracted (AVE) and composite reliability (CR) established the convergent and discriminant validity. Based on the results presented by the three assessment criteria in Table 2 (i.e. standardised factor loading, reliability and AVE), there is enough evidence to confirm the measurement model validity (Fornell \& Larcker, 1981).

\section{Table 2}

Confirmatory factor analysis (CFA). 


\begin{tabular}{|c|c|c|c|}
\hline Measure & $\begin{array}{c}\text { Factor } \\
\text { Loading } \\
\text { (FL) }\end{array}$ & $\begin{array}{c}\text { Composite } \\
\text { Reliability } \\
\text { (CR) }\end{array}$ & $\begin{array}{c}\text { Average } \\
\text { Variance } \\
\text { Extracted } \\
\text { (AVE) }\end{array}$ \\
\hline \multicolumn{2}{|c|}{ Internet Privacy Concerns } & 0.837 & 0.656 \\
\hline COL1 & 0.69 & & \\
\hline COL2 & 0.61 & & \\
\hline COL3 & 0.71 & & \\
\hline ERR1 & 0.55 & & \\
\hline ERR2 & 0.52 & & \\
\hline ERR3 & 0.52 & & \\
\hline CON1 & 0.53 & & \\
\hline CON2 & 0.66 & & \\
\hline CON3 & 0.62 & & \\
\hline Intrusiver & & 0.829 & 0.752 \\
\hline INT1 & 0.82 & & \\
\hline INT2 & 0.67 & & \\
\hline INT3 & 0.86 & & \\
\hline \multicolumn{2}{|c|}{ Personalisation } & 0.860 & 0.765 \\
\hline CRE1 & 0.80 & & \\
\hline CRE2 & 0.84 & & \\
\hline CRE3 & 0.83 & & \\
\hline LOC1 & 0.62 & & \\
\hline LOC2 & 0.58 & & \\
\hline LOC3 & 0.57 & & \\
\hline \multicolumn{2}{|c|}{ Monetary Rewards } & 0.901 & 0.872 \\
\hline MON1 & 0.88 & & \\
\hline MON2 & 0.88 & & \\
\hline MON3 & 0.84 & & \\
\hline \multicolumn{2}{|c|}{ MLBA Acceptance } & 0.902 & 0.875 \\
\hline ACC1 & 0.92 & & \\
\hline ACC2 & 0.91 & & \\
\hline ACC3 & 0.77 & & \\
\hline
\end{tabular}

Chi-square values are influenced by sample size, so incremental and absolute fit index values are used for measuring the performance of the measurement model. As shown in Table 3, the measurement fit indices (Chi-Square $=642.517$, Degree of Freedom $(D F)=$ $440, p<0.001$, adjusted goodness-of-fit index $(A G F I)=0.833$, comparative fit index $(\mathrm{CFI})$ $=0.965$, Trucker Lewis Index $(T L I)=0.958$, Root Mean Square Error of Approximation 
$($ RMSEA $)=0.043)$ were found to have adequately fit to data (Anderson \& Gerbing, 1988; Byrne, 2010; Bagozzi \& Yi, 1988). The AGFI should be at or above 0.80 (Chin \& Todd, 1995) whereas CFI should be at or above 0.90 (Bentler \& Bonett, 1980). The TLI is more restrictive and requires a value of 0.95 or above (Hu \& Bentler, 1999). Finally, the RMSEA should be less than 0.10 but it has also been recommended to represent a reasonable error of approximation if it is lower than the more restrictive threshold of 0.08 (Browne \& Cudeck, 1993). However, Hu \& Bentler (1999) recommended a RMSEA value of 0.06 as an indicative of good fit between the hypothesised model and the observed data. Table 3 shows these statistics, which were all found to be in accordance within the recommended levels.

\section{Table 3}

Results of measurement model.

\begin{tabular}{lll}
\hline Fit Indices & Cut-off Point & Measurement Model \\
\hline Chi-Square $\left(x^{2}\right) /$ Degree of Freedom (DF) & $\leq 3.000$ & $642.517 / 440=1.460$ \\
$p$ & $>0.001$ & $<0.001$ \\
AGFI & $\geq 0.800$ & 0.833 \\
CFI & $\geq 0.900$ & 0.965 \\
TLI & $\geq 0.950$ & 0.958 \\
RMSEA & $\leq 0.080$ & 0.043 \\
\hline
\end{tabular}

\subsection{Structural Model Testing}

Structural model testing analysed the relationships between the latent variables using AMOS 22.0. The analysis confirmed that the factor structure is an appropriate representation of the underlying data (Table 4). The test of overall model fit resulted in a $\chi^{2}$ value 426.848 with a degree of freedom of 276 and a probability value of $p<0.001$. The significance of $p$-value indicated that the absolute fit of the model was less than desirable (Dwivedi et al., 2017; Rana et al., 2016; Rana et al., 2017). Although the $\chi^{2}$ test of absolute model fit is sensitive to sample size and non-normality, a better measure of fit of $\chi^{2}$ over degree of freedom was considered. This ratio for the validated structural model for this study was found with the suggested bracket of [1-3] (Chin \& Todd, 1995; Gefen, Straub, \& Boudreau, 2000). We have also reported the AGFI, the CFI, and the TLI. Anderson \& 
Gerbing (1988) found CFI to be one of the most stable and strongest fit indices. We also report RMSEA, which measures discrepancy per degree of freedom (Steiger \& Lind, 1980).

\section{Table 4}

Results of structural model.

\begin{tabular}{lll}
\hline Fit Indices & Cut-off Point & Measurement Model \\
\hline Chi-Square $\left(\chi^{2}\right) /$ Degree of Freedom $(D F)$ & $\leq 3.000$ & $426.848 / 232=1.840$ \\
$p$ & $>0.001$ & $<0.001$ \\
AGFI & $\geq 0.800$ & 0.840 \\
CFI & $\geq 0.900$ & 0.952 \\
TLI & $\geq 0.950$ & 0.951 \\
RMSEA & $\leq 0.080$ & 0.058 \\
\hline
\end{tabular}

Having established the relative adequacy of the model fit, it was appropriate to examine the individual path coefficients corresponding to our hypotheses. This analysis is presented in Table 5. All four hypotheses were supported. The hypothesis reveals a negative and significant (i.e. $\beta=-0.156, p<0.050$ ) influence of internet privacy concerns on mobile location-based advertising (MLBA) acceptance. Similarly, intrusiveness was found to have a negative and significant (i.e. $\beta=-0.394, p<0.001$ ) impact on MLBA acceptance. However, both personalisation (i.e. $\beta=0.146, p<0.016$ ) and monetary rewards (i.e. $\beta=0.387, p<0.001$ ) were found to have positive and significant impact on MLBA acceptance.

\section{Table 5}

Path coefficients and Hypotheses testing. 


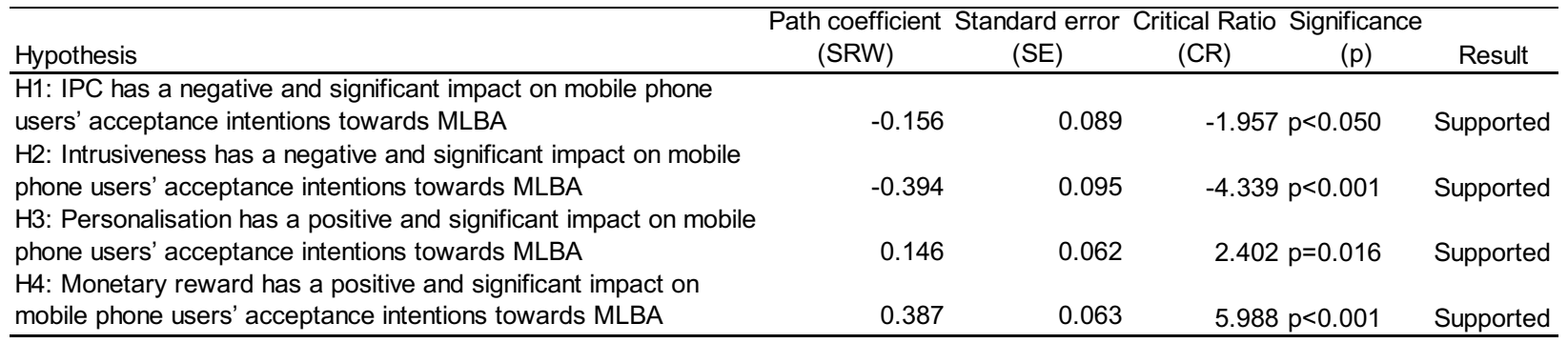

Figure 2 shows the validated research model with the path coefficients and significance of each relationship. It also illustrates the variance of the model on MLBA acceptance as $66 \%$.

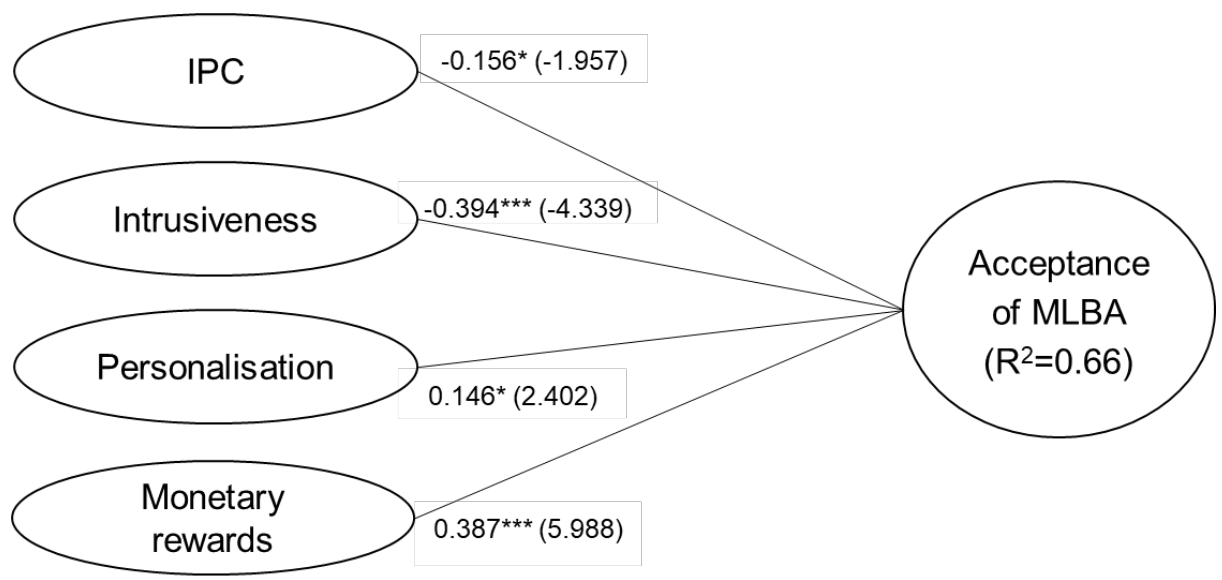

Fig. 2. Validated research model.

Further analysis was conducted using SAS Enterprise Guide 5.1 software to identify if any of those dimensions (IPC, intrusiveness, personalisation and monetary rewards) exhibits changes depending on the location of the participant (Europe or The Americas), their level of awareness (prior MLBA awareness) and their actual behaviour to allow mobile location tracking (never, sometimes, always).

To evaluate nationality influence, participants by area were identified and two representative areas were considered; Europe and The Americas. Twenty-three observations from countries outside these two areas were excluded for the analysis of variance. Consistent with the most influential predictors (intrusiveness and monetary 
rewards), the analysis reveals that intrusiveness is a significantly higher factor in Europe than in The Americas. On the contrary, The Americas is more incentivised to monetary rewards than Europe (see Table 6). Personalisation and IPC were not significantly different factors in these geographical areas.

\section{Table 6}

ANOVA results by geographical areas.

\begin{tabular}{|c|c|c|c|c|c|c|c|c|}
\hline Dimension & Level & Number & Mean & DF & $\begin{array}{r}\text { Sum of } \\
\text { Squares }\end{array}$ & $\begin{array}{r}\text { Mean } \\
\text { Square }\end{array}$ & F Ratio & Prob $>\mathrm{F}$ \\
\hline \multirow[t]{3}{*}{ Intrusiveness } & & & & 1 & 7.32314 & 7.32314 & 8.6616 & $0.0036^{*}$ \\
\hline & The Americas & 45 & 3.21 & & & & & \\
\hline & Europe & 184 & 3.66 & & & & & \\
\hline \multirow[t]{3}{*}{ Monetary rewards } & & & & 1 & 8.05184 & 8.05184 & 7.0157 & $0.0086^{*}$ \\
\hline & The Americas & 45 & 3.87 & & & & & \\
\hline & Europe & 184 & 3.40 & & & & & \\
\hline
\end{tabular}

Regarding levels of MLBA awareness, three dimensions were significant: Intrusiveness levels are lower for those participants who have prior knowledge and have received MBLA; while perceived benefits of personalisation and monetary rewards, are higher when participants have prior MLBA knowledge (see Table 7).

\section{Table 7}

ANOVA results by level of MLBA awareness.

\begin{tabular}{|c|c|c|c|c|c|c|c|c|}
\hline Dimension & Level & Number & Mean & DF & $\begin{array}{r}\text { Sum of } \\
\text { Squares }\end{array}$ & $\begin{array}{r}\text { Mean } \\
\text { Square }\end{array}$ & F Ratio & Prob $>\mathrm{F}$ \\
\hline \multirow[t]{4}{*}{ Intrusiveness } & & & & 2 & 10.1071 & 5.0536 & 5.9196 & $0.0031^{*}$ \\
\hline & No prior awareness & 36 & 3.78 & & & & & \\
\hline & Knew OR received MLBA & 67 & 3.75 & & & & & \\
\hline & Knew AND received MLBA & 149 & 3.35 & & & & & \\
\hline \multirow[t]{4}{*}{ Personalisation } & & & & 2 & 8.67664 & 4.3383 & 6.7143 & $0.0014^{*}$ \\
\hline & No prior awareness & 36 & 3.27 & & & & & \\
\hline & Knew OR received MLBA & 67 & 3.45 & & & & & \\
\hline & Knew AND received MLBA & 149 & 3.75 & & & & & \\
\hline \multirow[t]{4}{*}{ Monetary rewards } & & & & 2 & 13.9765 & 6.9882 & 6.3619 & $0.0020^{*}$ \\
\hline & No prior awareness & 36 & 3.38 & & & & & \\
\hline & Knew OR received MLBA & 67 & 3.18 & & & & & \\
\hline & Knew AND received MLBA & 149 & 3.72 & & & & & \\
\hline
\end{tabular}

When comparing each dimension by participants' actual behaviour in allowing mobile location tracking, all variables were significant including the acceptance of MLBA. Higher levels of risk (IPC and intrusiveness) are present for those who never allowed 
location tracking compared to those who always do. A similar pattern appears in the analysis of benefits (personalisation and monetary rewards) where participants who allow mobile location tracking perceive higher levels of benefits compared to those who never allow it (see Table 8).

\section{Table 8}

ANOVA results by participants' actual behaviour allowing mobile tracking.

\begin{tabular}{|c|c|c|c|c|c|c|c|c|}
\hline Dimension & Level & Number & Mean & DF & $\begin{array}{r}\text { Sum of } \\
\text { Squares }\end{array}$ & $\begin{array}{r}\text { Mean } \\
\text { Square }\end{array}$ & F Ratio & Prob $>F$ \\
\hline \multirow[t]{4}{*}{ MLBA Acceptance } & & & & 2 & 21.303 & 10.652 & 11.106 & $<.0001^{*}$ \\
\hline & Always & 33 & 3.59 & & & & & \\
\hline & Sometimes & 198 & 2.84 & & & & & \\
\hline & Never & 21 & 2.41 & & & & & \\
\hline \multirow[t]{4}{*}{ IPC } & & & & 2 & 11.239 & 5.620 & 11.968 & $<.0001^{*}$ \\
\hline & Always & 33 & 3.38 & & & & & \\
\hline & Sometimes & 198 & 3.91 & & & & & \\
\hline & Never & 21 & 4.24 & & & & & \\
\hline \multirow[t]{4}{*}{ Intrusiveness } & & & & 2 & 38.163 & 19.081 & 25.75 & $<.0001^{*}$ \\
\hline & Always & 33 & 2.66 & & & & & \\
\hline & Sometimes & 198 & 3.58 & & & & & \\
\hline & Never & 21 & 4.30 & & & & & \\
\hline \multirow[t]{4}{*}{ Personalisation } & & & & 2 & 14.919 & 7.459 & 12.011 & $<.0001^{*}$ \\
\hline & Always & 33 & 4.03 & & & & & \\
\hline & Sometimes & 198 & 3.60 & & & & & \\
\hline & Never & 21 & 2.95 & & & & & \\
\hline \multirow[t]{4}{*}{ Monetary rewards } & & & & 2 & 9.083 & 4.542 & 4.062 & $0.0184^{*}$ \\
\hline & Always & 33 & 3.93 & & & & & \\
\hline & Sometimes & 198 & 3.50 & & & & & \\
\hline & Never & 21 & 3.11 & & & & & \\
\hline
\end{tabular}

The results presented in this section show that the perceived benefits of disclosing location information outweigh the perceived risks associated with mobile phone users' acceptance of MLBA. Additionally, IPC, intrusiveness, personalisation and monetary rewards have a significant impact on MLBA acceptance $(\mathrm{H} 2, \mathrm{H} 3, \mathrm{H} 4$ and $\mathrm{H} 5$ accepted). It has also been identified that monetary rewards and intrusiveness have the most notable impacts. The implications of these findings are reviewed in the following section. 


\section{Discussion and implications}

These findings extend the current literature by evaluating simultaneously the role of four dimensions related to users' acceptance of MLBA: IPC, intrusiveness, personalisation and monetary rewards. The overall indications are that mobile users' MLBA acceptance is guided primarily by judgments on the perceived balance between intrusiveness and monetary rewards, and secondarily by their perceptions of personalisation or IPC. This has potential implications for both theory and practice by merchants, marketers, service providers, developers, privacy advocates, government legislators and any others considering the use of MLBA.

This research confirms that MLBA is a growing, entrepreneurial and innovative form of advertising, with over $80 \%$ of the sample respondents being aware of it and over $60 \%$ having already experienced this type of mobile device communication. The sample also indicated that, that despite any concerns about privacy or security, more than one in ten mobile users always allow mobile location tracking, a further almost eight in ten sometimes allow such tracking, while less than one in ten never allow it.

The differences outlined between Europe and The Americas are interesting, as they indicate a significant difference between the accepted levels of intrusiveness and monetary rewards in each area. The Americas appears to be more attracted to monetary rewards whereas, in Europe, intrusiveness is the principal factor. These cultural differences need further exploration, bearing in mind that, for example, comparisons between China and USA (Petina et al., 2016) indicated that such differences may not be due to cultural or personal traits, a possible explanation being that the infrastructure of the country and its technological environment are principal driving forces in the widespread take-up of mobile services in China.

This study extends prior research that assessed the impact of perceived risk and perceived benefit on acceptance intentions. Previous studies confirmed that personalisation and individuals' IPC are important determinants of MLBA and this research indicates that intrusiveness and monetary rewards are even stronger predictors. 
A possible explanation could be that mobile users are progressively coming to accept that sharing personal data is a growing part of modern life and that privacy and security concerns are better managed than they once were.

Previous research into PCT has shown that individuals are significantly less inclined to disclose personal information when presented with new and unfamiliar types of advertising due to an increase in the perception of risk, while perceived benefits make the disclosure of personal information more likely. The findings here are consistent with Keith et al. (2013), and support Xu et al. (2011), in suggesting that perceived benefit is a more important factor than perceived risk in determining the disclosure and acceptance intentions of an individual. It appears that users consider personal privacy loss acceptable, as long as it assures certain benefits and the level of risk is moderate (Petina et al., 2016). This means that an individual's concern for privacy is not absolute but may be traded off against benefits. Therefore, opportunities exist for offering MLBA, but this needs to be managed carefully and ethically. While the decision to share personal information should be a self-regulating process, the evidence suggests that users tend to trade-off their privacy for the benefits obtained, which could lead to the growth of privacyinvasive apps. However, the introduction of GDPR may prevent from this happening and allow users to be aware of the specific data that the service will be collecting, how that data will be used and, importantly, protect them when companies infringe this agreement (Wottrich et al., 2018).

The findings reveal the overall negative influence of IPC but also highlight some interesting variations within this overall indication. Considering the average IPC compared to actual behaviour (allowing mobile location tracking), there was a significant difference between those who always allowed tracking, IPC of 3.5, and those who never allowed tracking, IPC of 4.3, while those participants who indicated that they sometimes allowed tracking had an IPC of 3.9. Therefore, MLBA providers should aim to reduce perceived levels of privacy invasion through the implementation of privacy intervention strategies that follow the new data protection regulations. Seeking permission from the user for app installation is not enough in itself, as research shows that a statement that justifies the 
purpose of the permission request alleviates users' privacy concerns (Gu et al., 2017). For example, organisations could always request the consent of individuals for collecting and processing personal data by means of a clear affirmative action, omit the collection of excessive and unnecessary data, and ensure that there is a dedicated and consistent pattern surrounding their methodology and rationale for data collection. Rather than concealing privacy-related information for fear that it may discourage consumers from using a service, it seems that a better option is to raise awareness regarding the collection, use and control of personal information. Users will then be able to clearly assess the situation and avoid the feelings of intrusiveness that this research has found have a more significant impact that concerns of privacy. Additionally, it is important to make these efforts visible to consumers through a comprehensive and transparent privacy policy or through affiliations with initiatives such as TRUSTe (Rodrigues et al., 2016) who provide privacy certification and thus reduce the perceived risk of opportunistic behaviour. MLBA providers could also ensure that their applications have in-built privacy controls, allowing users to opt-out or de-activate the MLBA function, thus hiding their location anytime.

The findings reveal that in the context of MLBA, IPC is not a principal predictor, similar to previous research indicating that privacy concerns are not a valid predictor of privacy behaviour (Hallam \& Zanella, 2017). This research indicates that intrusiveness represents a better predictor of MLBA. This is interesting because, despite the key requirement for permission-based advertisement and greater control offered by smartphones (Watson, McCarthy, \& Rowley, 2013), intrusiveness is still highly salient and plays a significant role in determining acceptance of such mobile communications. Intrusiveness influences users' decisions to accept the permission request when the app is considered low-value. However, for apps deemed high-value, there is a tendency to trade off privacy despite the potential intrusiveness of the app (Wottrich et al., 2018). Therefore, marketers should be aware that consumers are more sensitive to feelings of irritation/annoyance from the interruptions of MLBA than by the fact that their personal data has been used. 
Liu et al. (2012) postulated that the ability of marketers to know the location of users potentially leads to greater perceptions of intrusiveness into mobile users' privacy. However, the findings of this study reveal that a consumer's perception of intrusiveness is a unique construct that reflects the highly personal nature of smartphones, regardless of their privacy concerns. This research emphasises the potentially interfering nature of MLBA, a consequence of which can be a rise in mobile user dissatisfaction. This implies that most consumers would be happy to disclose personal information if the communication and advertisement messages are less intrusive in terms of irritation, interference and annoyance. Although asking for permission is one way to overcome issues of privacy, other efforts need to be made to reduce mobile users' perceptions of intrusiveness. One way that providers could overcome the perceived intrusiveness of MLBA, apart from collectively agreeing to only send MLBA to customers who sign up for this type of communication, is granting control to consumers through customisation. This gives users the opportunity to customise the messages that they receive, potentially leading to stronger feelings of control and therefore a more positive attitude and higher acceptance level towards MLBA. Sundar \& Marathe (2010) predicted that consumers become more involved with an advertisement when they can perceive themselves as the source of information, and so tailoring information to suit individual interests could be expected to yield positive results. Additionally, location and time can be used to send messages to customers when they are at home rather than at work, as it has been found that mobile users are more receptive to such communications at the former rather than the latter (MillwardBrown, 2017).

This research also adds support to past studies (Baek \& Morimoto, 2012; Xu et al., 2011) that outlined the role of personalisation as a factor directly influencing MLBA acceptance. Consequently, providers of MLBA need to ensure their personalisation efforts include sending the most relevant message to mobile users at the most relevant time and when the user is in the most relevant location. Merchants should also continue efforts to develop bespoke customer views as they implement personalisation to increase MLBA effectiveness. Organisations should ensure that a strong relationship between them and the individual consumer has been established before any attempt to deliver 
advertising to consumers via their mobile devices.

The effect of monetary rewards was found to be a more significant driver for MLBA acceptance than personalisation. This implies that, while users welcome personalisation, monetary rewards have a higher compensating value for the perceived risk of accepting MLBA. In addition, this finding supports the notion that consumers are willing to disclose information to receive a promotion or discount (Premazzi et al., 2010; Ward, Bridges, \& Chitty, 2005). Lee, Kim, \& Sundar (2015) highlighted that monetary rewards do not diminish an individuals' information privacy concerns but that an individual's intention to provide sensitive information, such as location data, is higher when monetary rewards exist.

An important implication to highlight concerning the use of monetary rewards as a strategic opportunity for MLBA is the social and ethical concerns it raises. Offering monetary rewards in a relatively easy way for business to convince consumers to release their rights of privacy and, without perhaps being aware, accepting the potential risks of information disclosure, especially the triggering of ongoing location monitoring. Using monetary rewards to stimulate individuals to accept MLBA could be based on a type-ofcustomer evaluation. Loyal customers are more inclined to continue to share personal information such as location data (Lee \& Rha, 2016; Wottrich et al., 2018) and these are the individuals more suited to receiving monetary rewards. To access new customers, it is more appropriate and ethical to stimulate the receipt of their location data and ability to receive MLBA by ensuring the communication of relevant privacy policies, the transparent usage of collected information and granting control of personal information to these users. Moreover, as technology evolves, users are led into a complex web of connected elements that makes understanding the information exchange difficult, and hence responsibilities lie with the service provider to maintain transparency of their data protection practices to empower users to become more rational in their decision-making (Barth \& Jong, 2017; Wang et al., 2016).

\section{Conclusions}


This study advances the understanding of MLBA by providing a more comprehensive view of the key risk and benefit components that providers should consider for the successful application of such means of communication. The conceptual model proposed, based on PCT, was used to identify the most important benefits and risks. Four key factors were drawn from the literature: IPC, intrusiveness, personalisation and monetary rewards and, although further research is needed to achieve a more universal and comprehensive understanding of the principal determinants for MLBA, this exploratory research reveals intrusiveness to have a significantly higher negative influence than IPC and monetary rewards to be a notably more positive attraction than personalisation. It is therefore proposed that marketers should focus on reducing impressions of intrusiveness of MLBA by following strategies that grant control to the mobile user through permission-based customisation, while also ensuring that such communications are sent at an appropriate time and place. Monetary rewards also offer opportunities for enhancing the acceptance of MLBA, but this needs to be handled carefully considering the more pronounced impact of intrusiveness. The privacy calculus theory has been extensively used for research on these types of issues as it allows the assessment of the joint effects of perceived benefits and risk around privacy decision making.

A limitation of this research worth noting concerns the sampling method, as there may be environmental factors that are influencing the respondents' perspectives. For example, one-third of the sample was based in the United Kingdom (UK). In addition, the nature and design of EFA is exploratory and the results presented in the above sections provided initial evidence to recommend the use of confirmatory factor analysis and structural equation modelling (SEM) in future research. As the mobile device communications sector continues to evolve regarding both the technologies involved and the breadth of applications, it is also likely that user habits and preferences will continue to evolve and require further study. A similar survey with a larger and more international sample is needed to confirm these results and to enable cross-culture research that explores cultural moderators. More research could also integrate relevant aspects from other behavioural economic theories or examine how personality traits or demographic 
characteristics might influence acceptance of MLBA. Further research is also needed on any gaps between consumers' acceptance intentions for MLBA and actual behaviour, potentially using an experimental design to better manipulate the variables influencing consumer behaviour when receiving MLBA. Other research could also be undertaken on exploring MLBA issues for other smart-mobile devices such as watches, fitness straps and spectacles. This may become more relevant as the world moves closer towards the era of the 'Internet of Things' where all such devices are connected and capable of receiving and transmitting information, meaning that a detailed understanding of users' perceptions of MLBA and similar communication techniques becomes crucial.

\section{References}

Albert, T., Goes, P., \& Gupta, A. (2004). GIST: A Model for Design and Management of Content and Interactivity of Customer-Centric Web Sites, MIS Quarterly, 28(2), 161182.

Anderson, J. C., \& Gerbing, D. W. (1988). Structural equation modeling in practice: A review and recommended two-step approach. Psychological Bulletin, 103(3), 411-423.

Andrews, M., Goehring, J., Hui, S., Pancras, J., \& Thornswood, L. (2016). Mobile Promotions: A Framework and Research Priorities, Journal of Interactive Marketing, $34,15-24$.

Atkinson, L. (2013). Smart Shoppers? Using QR Codes and 'Green' Smartphone Apps to Mobilize Sustainable Consumption in the Retail Environment, International Journal of Consumer Studies, 374, 387-383.

Baek, T. H., \& Morimoto, M. (2012). Stay Away from Me, Journal of Advertising, 41(1), 59-76.

Bagozzi, R.P., Yi, Y. (1988). On the evaluation of structural equation models. J. Acad. Mark. Sci. 16 (1), 74-94.

Barth, S., \& de Jong, M. D. T. (2017). The privacy paradox: Investigating discrepancies between expressed privacy concerns and actual online behavior - A systematic literature review. Telematics and informatics, 34(7), 1038-1058.

Banerjee, S., \& Dholakia, R. (2008). Does location-based advertising work? International Journal of Mobile Marketing, 3(2), 68-74. 
Beldad, A., \& Kusumadewi, M. C. (2015). Here's my Location, for Your Information: The Impact of Trust, Benefits, and Social Influence on Location Sharing Application Use Among Indonesian University Students, Computers in Human Behavior, 49, 102-110. Bentler, P., \& Bonett, D. (1980). Significance tests and goodness of fit in the analysis of co-variance structures. Psychological Bulletin, 88(3), 588-606.

Browne, M. W., \& Cudeck, R. (1993). Alternative ways of assessing model fit. In K. A. Bollen, \& J. S. Long (Eds.), Testing structural equation models (pp. 136-162). Newbury Park, CA: Sage.

Byrne, B. (2010). Structural Equation Modeling with AMOS: Basic Concepts, Applications and Programming, 6th edition. Taylor \& Francis Group, New York, USA.

Chaffey, D., \& Chadwick E. F. (2012). Digital Marketing: Strategy, Implementation and Practice, Pearson Education Limited, $5^{\text {th }}$ Edition, 142-145.

Chin, W. W., \& Todd, P. A. (1995). On the use, usefulness, and ease of use of structural equation modeling in MIS research: A note of caution. MIS Quarterly, 19(2), 237-246.

Davies, S. G. (1997). Re-engineering the Right to Privacy: How Privacy Has Been Transformed from a Right to a Commodity, Technology and Privacy: The New Landscape. MIT Press.

Dinev, T., Heng X., Smith, H., \& Hart, P. (2013). Information Privacy and Correlates: An Empirical Attempt to Bridge and Distinguish Privacy-Related Concepts, European Journal of Information Systems, 22(3), 295-316.

Dwivedi, Y. K., Rana, N. P., Janssen, M., Lal, B., Williams, M. D., \& Clement, M. (2017). An empirical validation of a unified model of electronic government adoption (UMEGA). Government Information Quarterly, 34(2), 211-230.

Edwards, S. M., Li, H., \& Lee, J. H. (2002). Forced Exposure and Psychological Reactance: Antecedents and Consequences of the Perceived Intrusiveness of PopUp Ads, Journal of Advertising, 31(3), 83-95.

eMarketer (2016). Mobile Ad Spend to Top $\$ 100$ Billion Worldwide in 2016, 51\% of Digital Market. Available from: http://www.emarketer.com/Article/Mobile-Ad-Spend-Top-100Billion-Worldwide-2016-51-of-Digital-Market/1012299\#sthash.PYxsJ9gB.dpuf, accessed 31/5/18.

EU-DPR (2016). Data Protection Reform, European Commission. Available from: 
http://ec.europa.eu/newsroom/just/item-detail.cfm?item id=52404, accessed 31/5/18.

Field, A., \& Miles, J. (2010). Discovering Statistics Using SAS, London: SAGE Publications.

Fodor, M., \& Brem, A. (2015). Do privacy concerns matter for millennials? Results from an empirical analysis of location-based services adoption in Germany, Computers in Human Behavior, 53, 344-353.

Fornell, C., \& Larcker, D. F. (1981). Evaluating structural equation models with unobservable variables and measurement error. Journal of Marketing Research, 18(1), 39-50.

Gazley, A., Hunt, A., \& McLaren, L. (2015). The effects of location-based-services on consumer purchase intention at point of purchase, European Journal of Marketing, 49 (9/10), 1686-1708.

Geetha, V., \& Rangarajan, K. (2015). A Conceptual Framework for Perceived Risk in Consumer Online Shopping, Global Management Review, 10(1), 9-22.

Gefen, D., Straub, D. \& Boudreau, M.-C. (2000). Structural Equation Modeling and Regression: Guidelines for Research Practice, Communications of the Association for Information Systems, 4(7), 1-78.

Gu, J. Xu, Y., Xu, H., Zhang, C., \& Ling, H. (2017). Privacy concerns for mobile app download: An elaboration likelihood model perspective, Decision Support Systems, 94 , 19-29.

Hallam, C, \& Zanella, G. (2017). The privacy paradox explained as a temporally discounted balance between concerns and rewards, Computers in Human Behavior, 68, 217-227.

Hann, H. I., Hui K. L., Lee S. Y. T., \& Png, I.P.L. (2007). Overcoming Online Information Privacy Concerns: An Information-Processing Theory Approach, Journal of Management Information Systems, 24(2), 13-42.

Hong, W., \& Thong, J.Y.L. (2013). Internet Privacy Concerns: An Integrated Conceptualization and Four Empirical Studies, MIS Quarterly, 37(1), 275-298.

Hu, L. -T., \& Bentler, P. M. (1999). Cutoff criteria for fit indexes in covariance structure analysis: Conventional criteria versus new alternatives. Structural Equation Modeling: A Multidisciplinary Journal, 6(1), 1-55. 
Hühn, A. E., Khan, J. V., Ketelaar, P., van't Riet, J. J., Konig, R., Rozendaal, E., \& Markopoulos, P. (2017), Does location congruence matter? A field study on the effects of location-based advertising on perceived $A D$ intrusiveness, relevance \& value, Computers in Human Behavior, 73, 659-668.

Hui, K. L., Teo, H. H., \& Lee, S. Y. T. (2007). The Value of Privacy Assurance: An Exploratory Field Experiment, MIS Quarterly, 31(1), 19-33.

Hung, H., \& Wong, Y.H. (2009). Information Transparency and Digital Privacy Protection: Are they Mutually Exclusive in the Provision of E-Services? Journal of Services Marketing, 23(3), 154-164.

IABUK (2017). Internet Advertising Bureau UK: Mobile drives digital ad spend past $£ 10$ billion threshold. Available from: https://www.iabuk.com/press-release/mobile-drivesdigital-ad-spend-past-ps10-billion-threshold, accessed 31/5/18.

Jentzsch, N., Preibusch, S., \& Harasser, A. (2012), Study on Monetising Privacy: An Economic Model for Pricing Personal Information, European Network and Information Security Agency (ENISA), 1-76.

Junglas, I., \& Watson, R. T. (2006). The U-Constructs: Four Information Drives, Communications of the Association for Information Systems, 17, 569-592.

Junglas, I. A., Johnson, N. A., \& Spitzmuller, C. (2008). Personality Traits and Concern for Privacy: An Empirical Study in the Context of Location-Based Services, European Journal of Information Systems, 17(4), 387-402.

Kaplowitz, M., Hadlock, T., \& Levine, R. (2004). A comparison of web and mail survey response rates, Public Opinion Quarterly, 68(1), 94-101.

Keith, M. J., Babb, J. S., Furner, C. P., \& Abdullat, A. (2010). Privacy Assurance and Network Effects in the Adoption of Location-based Services: An IPhone Experiment, International Conference on Information Systems (ICIS '10), 1(1), 237.

Keith, M. J., Thompson, S. C., Hale, J. Lowry, P. B., \& Greer, C. (2013). Information Disclosure on Mobile Devices: Re-examining Privacy Calculus with Actual User Behavior, International Journal of Human-Computer Studies, 71, 1163-1173.

Kim, D. J. (2008). Self-Perception-Based Versus Transference-Based Trust Determinants in Computer-Mediated Transactions: A Cross-Cultural Comparison Study, Journal of Management Information Systems, 24(4), 13-45. 
Kim, Y. J., \& Han, J. Y. (2014). Why Smartphone Advertising Attracts Customers: A Model of Web Advertising, Flow, and Personalisation, Computers in Human Behaviour, 33, 256-269.

Kline, R. B. (2011). Principles and practice of structural equation modeling (3rd ed.). New York: The Guilford Press.

Koohikamali, M., Gerhart, N., \& Mousavizadeh, M. (2015). Location Disclosure on LBSNAs: The Role of Incentives on Sharing Behavior, Decision Support Systems, 71, 7887.

Krishen, A. S., Raschke, R. L., Close, A. G., \& Kachroo, P. (2017). A power-responsibility equilibrium framework for fairness: Understanding consumers' implicit privacy concerns for location-based services, Journal of Business Research, 73, 20-29.

Lee, H., Park, H., \& Kim, J. (2013). Why do people share their context information on Social Network Services? A qualitative study and an experimental study on users' behavior of balancing perceived benefit and risk, International Journal of HumanComputer Studies, 71 (Social Networks and Ubiquitous Interactions), 862-877.

Lee, H., Lim, D., Kim, H., Zo, H., \& Ciganek, A. P. (2015). Compensation paradox: the influence of monetary rewards on user behaviour, Behaviour \& Information Technology, 34(1), 45-56.

Lee, J., \& Rha, J. (2016). Personalization-privacy paradox and consumer conflict with the use of location-based mobile commerce, Computers in Human Behavior, 63, 453-462.

Lee, S., Kim, K. J., \& Sundar, S. S. (2015). Customization in location-based advertising: Effects of tailoring source, locational congruity, and product involvement on ad attitudes, Computers in Human Behavior, 51(Part A), 336-343.

Li, H., Sarathy, R., \& Xu, H. (2011). The role of affect and cognition on online consumers' decision to disclose personal information to unfamiliar online vendors, Decision Support Systems, 51(3), 434-445.

Liu, C., Sinkovics, R., Pezderka, N., \& Haghirian, P. (2012). Determinants of Consumer Perceptions toward Mobile Advertising - A Comparison between Japan and Austria. Journal of Interactive Marketing, 26(1), 21-32.

Limpf, N., \& Voorveld, H.A.M. (2015). Mobile Location-Based Advertising: How Information Privacy Concerns Influence Consumers' Attitude and Acceptance, Journal 
of Interactive Advertising, 15(2), 111-123.

Lowry, P. B., Moody, G. D., Vance, A., Jensen, M., Jenkins, J. L., \& Wells, T. M. (2012). Using an Elaboration Likelihood Approach to Better Understand the Persuasiveness of Website Privacy Assurance Cues for Online Consumers, Journal of the American Society for Information Science and Technology, 63(4), 755-776.

Malhotra, N.K., Kim S. S., \& Agarwal, J. (2004). Internet Users' Information Privacy Concerns (IUIPC): The Construct, the Scale, and a Causal Model, Information Systems Research, 15(4), 336-355.

MillwardBrown (2017). AdReaction: Gen X, Y and Z. Kantar Millward Brown. Available from: http://www.millwardbrown.com/adreaction/genxyz/global/what-you-should-doabout-it/catch-people-where-theyre-watching, accessed 31/5/18.

Okazaki, S., Li, H., \& Hirose, M. (2009). Consumer Privacy Concerns and Preference for degree of regulatory control, Journal of Advertising, 38(4), 63-77.

Park, D. Y., \& Goering, E. M. (2016). The Health-Related Uses and Gratifications of YouTube: Motive, Cognitive Involvement, Online Activity, and Sense of Empowerment, Journal of Consumer Health on the Internet, 20(1-2), 52-70.

Pentina, I., Zhang, L., Bata, H., \& Chen, Y. (2016). Exploring privacy paradox in information-sensitive mobile app adoption: A cross-cultural comparison, Computers in Human Behavior, 65, 409-419.

Premazzi, K., Castaldo, S., Grosso, M., Raman, P., Brudvig, S., \& Hofacker, C. F. (2010). Customer Information Sharing with E-Vendors: The Roles of Incentives and Trust, International Journal of Electronic Commerce, 14(3), 63-91.

Rana, N. P., Dwivedi, Y. K., Lal, B., Williams, M. D., \& Clement, M. (2017). Citizens' adoption of an electronic government system: Towards a unified view. Information Systems Frontiers, 19(3), 549-568.

Rana, N.P., Dwivedi, Y.K., Williams, M.D., and Weerakkody, V. (2016). Adoption of Online Public Grievance Redressal System in India: Toward Developing a Unified View. Computers in Human Behavior, 59, 265-282.

Rau, P. L. P., Zhang, T., Shang, T., \& Zhou, J. (2011). Content Relevance and Delivery Time of SMS Advertising, International Journal of Mobile Communications, 9(1), 1938. 
Robins, F. (2003). The Marketing of 3G, Marketing Intelligence and Planning, 21(6), 370378.

Rodrigues, R., Barnard-Wills, D., De Hert, P., \& Papakonstantinou, V. (2016). The future of privacy certification in Europe: an exploration of options under article 42 of the GDPR. International Review of Law, Computers \& Technology, 30(3), 248-270.

Shah, M. H., Peikari, H. R., \& Yasin, N. M. (2014). The determinants of Individuals' Perceived E-Security: Evidence from Malaysia, International Journal of Information Management, 34(1), 48-57.

Sheng, H., Nah, F. F. H., \& Siau, K. (2008). An Experimental Study on Ubiquitous Commerce Adoption: Impact of Personalisation and Privacy Concerns, Journal of the Association for Information Systems, 9(6), 344-376.

Smith, H. J., Dinev, T., \& Xu, H. (2011). Information Privacy Research: An Interdisciplinary Review, MIS Quarterly, 35(4), 989-1015.

Steiger, J. H., \& Lind, J. C. (1980). Statistically-based tests for the number of common factors. Annual Spring Meeting of the Psychometric Society, lowa City (pp. 424-453).

Sultan, F., Rohm, A. J., \& Gao, T. T. (2009). Factors Influencing Consumer Acceptance of Mobile Marketing: A Two-Country Study of Youth Markets, Journal of Interactive Marketing, 23, 208-320.

Sun, Y., Wang, N., Shen, X., \& Zhang, J. X. (2015). Location information disclosure in location-based social network services: Privacy calculus, benefit structure, and gender differences, Computers in Human Behavior, 52, 278-292.

Sundar, S. S., \& Marathe, S. S. (2010). Personalisation versus Customization: The Importance of Agency, Privacy, and Power Usage, Human Communication Research, 36(3), 298-322.

Sutanto, J., Palme, E. Tan, C. H., \& Pang, C. W. (2013). Addressing the PersonalizationPrivacy Paradox: An Empirical Assessment form a Field Experiment on Smartphone Users, MIS Quarterly, 37(4), 1141-1164.

Truong, Y., \& Simmons, G. (2010). Perceived Intrusiveness in Digital Advertising: Strategic Marketing Implications, Journal of Strategic Marketing, 18(3), 239-256.

Ünal, S., Ercis, A., \& Keser, E. (2011). Attitudes towards Mobile Advertising - A Research to Determine the Differences between the Attitudes of Youth and Adults, Social and 
Behavioral Science, 24, 361-377.

Unni, R., \& Harmon, R. (2007). Perceived Effectiveness of Push vs. Pull Mobile LocationBased Advertising, Journal of Interactive Advertising, 7(2), 1-24.

Varnali, K. (2012). SMS Advertising: How Message Relevance is Linked to the Attitude Toward the Brand? Journal of Marketing Communications, 1(1), 1-13.

Wang, T., Duong, T., \& Chen, C. (2016). Intention to disclose personal information via mobile applications: A privacy calculus perspective, International Journal of Information Management, 36, 531-542.

Ward, S., Bridges, K., \& Chitty, B. (2005). Do Incentives Matter? An Examination of Online Privacy Concerns and Willingness to Provide Personal and Financial Information, Journal of Marketing Communications, 11(1), 21-40.

Watson, C., McCarthy, J., \& Rowley, J. (2013), Consumer attitudes towards mobile marketing in the smart phone era, International Journal of Information Management, 33, 840-849.

Wehmeyer, K. (2007). Mobile Ad Intrusiveness - The Effects of Message Type and Situation, eMergence: Merging and Emerging Technologies Processes, and Institutions, 6(1), 1-18.

Wottrich, V., van Reijmersdal, E., \& Smit, E. (2018). The privacy trade-off for mobile app downloads: The roles of app value, intrusiveness, and privacy concerns, Decision Support Systems, 106, 44-52.

Xie, E., Teo, H. H., \& Wan, W. (2006). Volunteering Personal Information on the Internet: Effects of Reputation, Privacy Notices, and Rewards on Online Consumer Behavior, Marketing Letters, 17(1), 61-74.

Xu, D. J., Liao, S. S., \& Li, Q. (2008). Combining Empirical Experimentation and Modeling Techniques: A Design Research Approach for Personalized Mobile Advertising Applications, Decision Support Systems, 44(3), 710-724.

Xu, H., Oh, L. B., \& Teo, H. H. (2009). Perceived Effectiveness of Text vs. Multimedia Location-Based Advertising Messaging, International Journal of Mobile Communications, 7(2), 154-177.

Xu, H., Teo, H. H. Tan, B.C.Y., \& Agarwal, R. (2009). The Role of Push-Pull Technology in Privacy Calculus: The Case of Location-Based Services, Journal of Management 
Information Systems, 26(3), 135-173.

Xu, H., Luo, X. R., Carroll, J. M., \& Rosson, M. B. (2011). The Personalisation Privacy Paradox: An Exploratory Study of Decision Making Process for Location-Aware Marketing, Decision Support Systems, 51, 42-52.

Zhao, L., Lu, Y., \& Gupta, S. (2012). Disclosure Intention of Location-Related Information in Location-Based Social Network Services. International Journal of Electronic Commerce, 16(4), 53-90.

Zhu, H., Ou, C. X. J., van den Heuvel, W., \& Liu, H. (2017). Privacy calculus and its utility for personalization services in e-commerce: An analysis of consumer decision-making, Information \& Management, 54, 427-437. 


\section{Appendix A: Construct items}

\begin{tabular}{|c|c|c|}
\hline Construct & Item & References \\
\hline \multirow[t]{13}{*}{$\overline{\mathrm{IPC}}$} & Data Collection & \\
\hline & $\begin{array}{l}\text { COL1. It bothers me when companies track my location through my mobile phone. } \\
\text { COL2. When companies ask to track my location through my mobile phone, I think } \\
\text { twice before allowing this information. }\end{array}$ & $\begin{array}{l}\text { Hong \& } \\
\text { Thong (2013) }\end{array}$ \\
\hline & $\begin{array}{l}\text { COL3. I am concerned that companies are collecting too much location information } \\
\text { about me through my mobile phone. }\end{array}$ & \\
\hline & Secondary Usage of Data & \\
\hline & Control of Data & \\
\hline & $\begin{array}{l}\text { CON1. It bothers me if companies collect my mobile location and I cannot alter the } \\
\text { location settings. }\end{array}$ & \\
\hline & $\begin{array}{l}\text { CON2. It bothers me when I do not have control over how my mobile location is used } \\
\text { by companies. }\end{array}$ & \\
\hline & $\begin{array}{l}\text { CON3. I am concerned when companies reduce my control over my mobile location } \\
\text { information. }\end{array}$ & \\
\hline & Awareness of Data Usage & \\
\hline & Error & \\
\hline & $\begin{array}{l}\text { ERR1: Companies should take more steps to make sure that the personal } \\
\text { information in their files is accurate. }\end{array}$ & \\
\hline & $\begin{array}{l}\text { ERR2: Companies should have better procedures to correct errors in personal } \\
\text { information. }\end{array}$ & \\
\hline & $\begin{array}{l}\text { ERR3: Companies should devote more time and effort to verifying the accuracy of } \\
\text { the personal information in their databases. }\end{array}$ & \\
\hline \multirow[t]{8}{*}{ Personalisation } & Content Relevance & \\
\hline & $\begin{array}{l}\text { CRE1: I feel that mobile location-based advertising can provide me with the kind of } \\
\text { ads I might like. }\end{array}$ & $\begin{array}{l}\text { Xu et al. } \\
\text { (2009); Lee \& }\end{array}$ \\
\hline & $\begin{array}{l}\text { CRE2. It is important that mobile advertising have relevant information tailored to my } \\
\text { personal interests. }\end{array}$ & Rha (2016) \\
\hline & $\begin{array}{l}\text { CRE3. I feel that mobile location-based advertising would tailor to my needs. } \\
\text { Locatability }\end{array}$ & \\
\hline & $\begin{array}{l}\text { LOC1. Is important that mobile location-based advertising give me access to relevant } \\
\text { information at the right place. }\end{array}$ & $\begin{array}{l}\text { Xu et al. } \\
\text { (2009); Xu et }\end{array}$ \\
\hline & $\begin{array}{l}\text { LOC2. Is important that mobile location-based advertising give me up-to-date } \\
\text { information. }\end{array}$ & $\begin{array}{l}\text { al. (2014); } \\
\text { Kim \& Han }\end{array}$ \\
\hline & LOC3. It is important that mobile location-based advertising is delivered in a timely & $(2014)$ \\
\hline & way. & \\
\hline \multirow[t]{2}{*}{$\begin{array}{l}\text { Perceived } \\
\text { Intrusiveness }\end{array}$} & INT1. I feel that mobile location-based advertising is irritating. & $\begin{array}{l}\text { Kim \& Han } \\
(2014)\end{array}$ \\
\hline & $\begin{array}{l}\text { INT2. I feel that mobile location-based advertising is interfering. } \\
\text { INT3. I feel mobile location-based advertising is too annoying. }\end{array}$ & \\
\hline \multirow[t]{2}{*}{$\begin{array}{l}\text { Monetary } \\
\text { rewards }\end{array}$} & $\begin{array}{l}\text { ENG1. I am satisfied to get mobile location-based advertising that includes offers or } \\
\text { rewards. }\end{array}$ & $\begin{array}{l}\text { Ünal, Ercis, \& } \\
\text { Keser (2011) }\end{array}$ \\
\hline & $\begin{array}{l}\text { ENG2. I am more incline to accept mobile location-based advertising if it includes } \\
\text { offers or rewards that I might like. } \\
\text { ENG3. I will pay attention to mobile location-based advertising if I get an acceptable } \\
\text { offer or reward. }\end{array}$ & \\
\hline \multirow{2}{*}{$\begin{array}{l}\text { Acceptance of } \\
\text { MLBA }\end{array}$} & ACC1. I think I will use mobile location-based advertising to receive ads. & \\
\hline & $\begin{array}{l}\text { ACC2. I intend to accept mobile location-based advertising messages in the future. } \\
\text { ACC3. It is likely that I am going to accept mobile location-based advertising to } \\
\text { purchase. }\end{array}$ & $\begin{array}{l}\text { Xu, Liao \& Li } \\
\quad(2008)\end{array}$ \\
\hline
\end{tabular}

